\title{
Breast-feeding Performance Index: a composite index to describe overall breast-feeding performance among infants under 6 months of age
}

\author{
Upul Senarath ${ }^{1}$, Michael J Dibley ${ }^{2, *} \dagger$ and Kingsley E Agho ${ }^{3}$ \\ 'Department of Community Medicine, Faculty of Medicine, University of Colombo, Colombo, Sri Lanka and Visiting \\ Fellow, University of Newcastle, Callaghan, New South Wales, Australia: ${ }^{2}$ Centre for Clinical Epidemiology \\ and Biostatistics, Faculty of Health, University of Newcastle, Callaghan, New South Wales, Australia: ${ }^{3}$ School of \\ Public Health, University of Sydney, Sydney, New South Wales, Australia
}

Submitted 14 December 2005: Accepted 19 0ctober 2006: First published online 27 February 2007

\begin{abstract}
Objectives: To develop a composite index to describe the overall breast-feeding performance of infants $<6$ months of age; and, using this index, to identify the factors associated with poor breast-feeding practices and the association between breastfeeding and infant morbidity.

Design, setting and subjects: The 2003 Demographic and Health Survey was a multistage cluster sample survey of 4320 households in Timor-Leste which covered 573 infants aged $<6$ months. Breast-feeding Performance Index (BPI) was constructed by allocating one point for each of seven infant feeding practices: first suckling within an hour of birth; absence of prelacteals; non-use of feeding bottles; current breastfeeding; not receiving liquids; not receiving formula or other milk; and not receiving solids in the last 24 hours. BPI was treated as the dependent variable in univariate and multivariate analyses to identify the factors associated with poor breast-feeding.

Results: Exclusive breast-feeding rate was 29.9\%. The BPI (mean 4.4, standard deviation 1.77) was categorised as low, average and high according to tertiles. Multivariate analysis indicated that infants from the richest households were 1.70 (95\% confidence interval (CI) 1.04-2.77) times more likely to have 'low BPI' than the poorest. Maternal BMI $<18.5 \mathrm{~kg} \mathrm{~m}^{-2}$ was predictive of poor breast-feeding (odds ratio $=1.79 ; 95 \%$ CI 1.27-2.52). In the 'low' BPI group, the incidence of diarrhoea (13.4\%) and acute respiratory infections (20.7\%) during the previous two weeks was significantly higher than in 'average' (4.3 and 9.3\%) and 'high' BPI groups (4.6 and $5.5 \%$ ).

Conclusions: Creating a composite index to assess the overall breast-feeding performance among infants $<6$ months of age is feasible. BPI can be effectively used to identify target groups for breast-feeding promotion interventions.
\end{abstract}

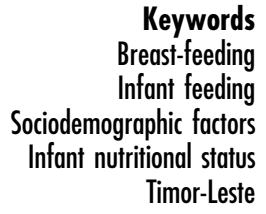

Breast-feeding (nting Timor-Leste
Composite child feeding indices are becoming increasingly important in the measurement of health outcomes of feeding practices, identification of determinants of poor feeding performance and evaluation of the effectiveness of nutritional interventions ${ }^{1-3}$. The main advantage of creating an index is that it can capture multiple dimensions of infant feeding practices into a single summary variable that can be used in the analyses of relationships with potential risk factors or health outcomes ${ }^{3}$. However, most

†Correspondence address: Centre for Clinical Epidemiology \& Biostatistics, Room 353, David Maddison Clinical Sciences Building, Royal Newcastle Hospital, Newcastle, New South Wales 2300, Australia. previous research on associations between breast-feeding practices and health outcomes of infants have only considered the individual breast-feeding indicators such as exclusive breast-feeding, full breast-feeding and bottlefeeding rates ${ }^{4-6}$. A large body of literature discusses predictive or risk factors of breast-feeding performance in different parts of the world, and the majority of these studies also focused on individual dimensions of breastfeeding $^{7-9}$.

Breast-feeding status among infants $<6$ months of age constitutes several dimensions including timely initiation, exclusiveness, and whether or not the infant is given prelacteal feeds and bottle-feeds. The World Health Organization (WHO) infant feeding guidelines 
recommend that infants should be exclusively breast-fed for the first six months of life to achieve optimal growth, development and health ${ }^{10}$. It is estimated that $10-15 \%$ of deaths among the under-fives in resource-poor countries could be prevented through achievement of universal coverage of exclusive breast-feeding alone ${ }^{11}$. In order to ensure success in breast-feeding, it is important that it be initiated as early as possible after delivery, preferably in the first hour of life $\mathrm{e}^{12}$. The avoidance of exposure to pacifiers and prelacteal feeds is important for successful breast-feeding since such exposures are associated with low exclusive breast-feeding ${ }^{13,14}$. Breast-fed infants have a lower incidence of infections and better cognitive development than bottle-fed infants ${ }^{15,16}$, and this indicates the need for taking into account bottle-feeding status in quantifying the overall breast-feeding performance.

Creating a child feeding index would be both feasible and useful, especially to quantify the strength of the association between child feeding practices and nutritional outcomes, and to study maternal and socioeconomic barriers to optimal feeding practices ${ }^{2}$. A previous group has developed an age-specific composite feeding index for children aged 6-36 months using Demographic and Health Survey (DHS) data ${ }^{2,3}$. The index was created by combining information on the key dimensions of child feeding practices based on current feeding recommendations for children 6-36 months of age $^{2,3}$. Subsequently, this index has been used to estimate the strength of the association between child feeding practices and child nutritional indicators such as heightfor-age $Z$-scores ${ }^{3,17,18}$. The usefulness of an overall breastfeeding score in programme evaluations should not be underestimated since most programmes address more than a single breast-feeding behaviour ${ }^{19-21}$. An overall breast-feeding behaviour score has been used in an evaluation of the impact of community-based strategies for improving breast-feeding practices in Ghana ${ }^{1}$. The score was derived from five ideal breast-feeding behaviours: giving colostrum to newborns; not giving water; not giving watery foods; never using a feeding bottle; and current breast-feeding status ${ }^{1}$.

However, a search of the literature shows a consistent lack of such an index for infants $<6$ months of age, whom depend on breast-feeding alone. The Timor-Leste 2003 DHS is a useful and valid source of information on infant and child feeding practices from a representative national sample of women of reproductive age and their pre-school-aged children ${ }^{22}$. This secondary data analysis of the Timor-Leste 2003 DHS aims to develop a valid composite index (Breast-feeding Performance Index) to describe the overall breast-feeding performance in infants $<6$ months of age. It also aims to identify the factors associated with poor breast-feeding performance and to establish the association between breast-feeding and infant morbidity outcomes using this index.

\section{Methods}

The data source for the present study was the Timor-Leste 2003 DHS. This cross-sectional household survey was conducted over four months from May to August 2003, using a multi-stage cluster sampling method to recruit into the survey 4320 households from four different geographic areas in the country. The urban stratum was drawn from Dili, Bacau and other smaller district towns; the rural west stratum included the three most western districts; the rural central stratum included six mainly mountainous districts; and the rural east stratum included the three most eastern districts. From the sampled households, 4177 eligible women were interviewed about their children born in the five years preceding the survey using a structured pre-coded questionnaire. The response rates for individual interviews with women were very high (98.4\%) and similar across each stratum. Of the 5790 children under 5 years old recruited into the survey, there were 573 infants $<6$ months of age.

In this survey, mothers were asked how soon after birth the baby was given breast milk and whether the child was given anything other than breast milk during the first three days of life before the mother started breast-feeding regularly. Information about current feeding practices was obtained by asking about breast-feeding and any other foods or liquids given to the child in the 24 hours prior to the interview. The household wealth index was based on information collected about 22 household assets and facilities ${ }^{23,24}$. The principal components statistical procedure was used to determine the weights for this index, which was subsequently divided into three categories. The bottom $40 \%$ of households was arbitrarily referred to as poorest households, the next $40 \%$ as the middle households, and the top 20\% as richest households.

Women were also questioned about whether their infants had experienced cough or diarrhoea at any time during the two weeks prior to the interview. Infants who had cough with difficult or short rapid breathing irrespective of fever were considered as having acute respiratory infections. The prevalence of diarrhoea was defined as the percentage of infants ill with diarrhoea as reported by the mother (or guardian) at any time during the two weeks preceding the interview. The weights and heights of the mothers were measured using standardised procedures described in the Timor-Leste 2003 DHS report $^{22}$. The survey design, sampling, survey instruments, survey organisation and nutritional status measurements have been described in detail elsewhere ${ }^{22}$.

\section{Data analysis}

Data analysis was performed using the 'SVY' commands of Stata version 9.0 (Stata Corp) to adjust for the cluster sampling design and to apply appropriate sampling weights. In keeping with the global infant feeding recommendations, seven dimensions were identified as 
important in describing the overall breast-feeding performance among infants aged $<6$ months. These dimensions were: (1) first suckling within an hour of birth; (2) absence of prelacteal feeds during the first three days of life; (3) non-use of feeding bottles/teats in the last 24 hours; (4) breast-feeding in the last 24 hours; (5) not receiving water or water-based liquids (with the exception of drops or syrups consisting of vitamins, mineral supplements or medicines) in the last 24 hours; (6) not receiving formula milk or any other milk in the last 24 hours; and (7) not receiving solids or semi-solids in the last 24 hours. The Breast-feeding Performance Index (BPI) was constructed by combining these seven dimensions into a single composite index by scoring one point for each dimension (Table 1). The scoring system gives BPI of an individual a value between 0 and 7 .

Assigning equal weights (one point) for each dimension was based on the assumption that each practice was equally important. Since this is an arbitrary assignment of weights, the principal components analysis (PCA) method was also used to assign weights for individual indicators and subsequently to create a standardised index. The PCA procedure consolidated the seven dimensions under consideration into a single dimension using weighted scores. The PCA method has been previously used to assign weights in constructing a household wealth index using household assets data in national representative surveys $^{23,24}$. According to individual BPI values by the equal weight and PCA methods, each infant was assigned to one of the tertiles in the sample. The bottom 33.3\% of infants was arbitrarily referred to as 'low BPI', the next $33.3 \%$ as 'average BPI', and the top 33.3\% as 'high BPI'.

Table 1 Feeding practices among infants aged $<6$ months and scoring system for the Breast-feeding Performance Index (BPI)

\begin{tabular}{|c|c|c|c|}
\hline Practice & $n$ & $\%$ & Score for BPI \\
\hline \multicolumn{4}{|l|}{ First suckling } \\
\hline$<1 \mathrm{~h}$ & 274 & 47.9 & 1 \\
\hline$\geq 1 \mathrm{~h}$ & 299 & 52.1 & 0 \\
\hline \multicolumn{4}{|c|}{ Prelacteals in first 3 days } \\
\hline Not given & 375 & 65.4 & 1 \\
\hline Given & 198 & 34.6 & 0 \\
\hline \multicolumn{4}{|c|}{ Current breast-feeding* } \\
\hline Yes & 553 & 96.5 & 1 \\
\hline No & 20 & 3.5 & 0 \\
\hline \multicolumn{4}{|c|}{ Feeding bottle use* } \\
\hline No & 519 & 90.6 & 1 \\
\hline Yes & 54 & 9.4 & 0 \\
\hline \multicolumn{4}{|l|}{ Liquids* } \\
\hline Not given & 312 & 54.4 & 1 \\
\hline Given & 261 & 45.6 & 0 \\
\hline \multicolumn{4}{|c|}{ Formula/other milk* } \\
\hline Not given & 227 & 39.7 & 1 \\
\hline Given & 346 & 60.3 & 0 \\
\hline \multicolumn{4}{|l|}{ Solids* } \\
\hline Not given & 300 & 52.3 & 1 \\
\hline Given & 273 & 47.7 & 0 \\
\hline Total & 573 & 99.8 & 7 \\
\hline
\end{tabular}

* During the past 24 hours.
Correlation coefficients were calculated between the proportions of infants belonging to each sociodemographic category according to BPI tertiles by the PCA method and the equal weight method. The correlation coefficient of the BPI tertiles between the equal weight method and the PCA method was highly significant $(r=0.9346, \quad P<0.0001)$ indicating a strong linear relationship between the two methods. The proposed method, with equal weights for each feeding dimension, was used in the subsequent analyses because of its simplicity.

BPI was treated as the dependent variable in the univariate and multivariate analyses to identify the factors associated with poor breast-feeding. The associations between 'low BPI' (lower 33.3\% of BPI) and geographical region, ecological zone, household wealth index, mother's working status, maternal educational level, maternal age, place of delivery, birth order, sex of infant and maternal body mass index (BMI, weight/height ${ }^{2}$ ) were examined by unadjusted odds ratios (ORs) and 95\% confidence intervals (CIs). All of the independent variables were then entered into a multivariate model to estimate the unconfounded associations by adjusted ORs and 95\% CIs. In order to establish the association between BPI and infant morbidity, the proportion of infants with diarrhoea or acute respiratory infections in each BPI category was estimated, and the differences between proportions were evaluated using 95\% CI.

\section{Results}

The proportion of mothers who complied with each of the seven breast-feeding practices under consideration is presented in Table 1. Although 96\% of the infants $<6$ months old were currently breast-fed during the previous 24 hours, the exclusive breast-feeding rate was $29.9 \%$. In this population, a high proportion of the breast-fed infants received artificial milk (60.3\%), solids (47.7\%) and other liquids (45.6\%). Approximately $48 \%$ of the $<6$-month-old infants had breast-feeding initiated within the first hour of birth, and 9.4\% were fed with bottles.

Table 2 illustrates that, despite a high and relatively consistent current breast-feeding rate, practices such as timely first suckling, bottle-feeding and receiving supplementary feeds varied with sociodemographic characteristics and maternal BMI. Infants from the rural west region showed the highest rates for some practices (timely first suckling 76.2\%, absence of bottle-feeding 99.0\%), but the worst performance with respect to exclusiveness of breast-feeding (artificial milk 81.2\%, solids 61.4\%, liquids $49.5 \%)$ compared with other regions. Mothers from the richest households consistently reported poorer breastfeeding practices than mothers from the middle and the poorest households, mainly due to higher rates of feeding artificial milk and use of feeding bottles. Infants born in health facilities were more likely to be delayed in initiating 
Table 2 Feeding practices among infants aged $<6$ months by sociodemographic characteristics $(n=573)$

\begin{tabular}{|c|c|c|c|c|c|c|c|c|}
\hline \multirow[b]{2}{*}{ Characteristic } & \multirow[b]{2}{*}{$n$} & \multicolumn{7}{|c|}{$\%$ of infants } \\
\hline & & $\begin{array}{c}\text { Timely } \\
\text { first suckling }\end{array}$ & $\begin{array}{l}\text { Prelacteals } \\
\text { given }\end{array}$ & $\begin{array}{l}\text { Currently } \\
\text { breast-fed }\end{array}$ & Bottle-fed & Liquids given & Formula/other milk given & Solids given \\
\hline \multicolumn{9}{|l|}{ Geographical region } \\
\hline Urban & 152 & 41.7 & 41.0 & 95.8 & 20.1 & 46.5 & 63.2 & 45.8 \\
\hline Rural west & 115 & 76.2 & 32.7 & 95.1 & 1.0 & 49.5 & 81.2 & 61.4 \\
\hline Rural central & 156 & 51.0 & 34.2 & 96.0 & 7.4 & 39.6 & 49.7 & 40.9 \\
\hline Rural east & 150 & 34.3 & 30.7 & 98.0 & 6.6 & 51.8 & 61.3 & 51.8 \\
\hline$P$-value & & 0.000 & 0.326 & 0.354 & 0.000 & 0.043 & 0.000 & 0.010 \\
\hline \multicolumn{9}{|l|}{ Ecological zone } \\
\hline Lowland & 481 & 45.8 & 36.3 & 96.9 & 9.3 & 47.2 & 63.4 & 50.6 \\
\hline Highland & 92 & 57.0 & 28.2 & 94.6 & 9.8 & 38.7 & 45.6 & 34.6 \\
\hline$P$-value & & 0.060 & 0.193 & 0.316 & 0.886 & 0.068 & 0.007 & 0.006 \\
\hline \multicolumn{9}{|l|}{ Household wealth index } \\
\hline Poorest & 225 & 52.7 & 29.7 & 96.4 & 5.2 & 39.3 & 54.1 & 43.4 \\
\hline Middle & 235 & 46.4 & 36.8 & 97.1 & 7.1 & 52.3 & 60.5 & 51.5 \\
\hline Richest & 113 & 41.4 & 40.7 & 95.4 & 22.5 & 44.7 & 70.8 & 50.8 \\
\hline$P$-value & & 0.115 & 0.048 & 0.629 & 0.000 & 0.009 & 0.012 & 0.192 \\
\hline \multicolumn{9}{|l|}{ Maternal working status } \\
\hline Working & 279 & 47.9 & 36.3 & 96.9 & 7.6 & 46.1 & 58.4 & 46.5 \\
\hline Non-working & 294 & 47.9 & 33.3 & 96.1 & 11.3 & 45.2 & 61.7 & 48.6 \\
\hline$P$-value & & 0.990 & 0.431 & 0.424 & 0.077 & 0.844 & 0.434 & 0.626 \\
\hline \multicolumn{9}{|l|}{ Maternal education } \\
\hline No education & 253 & 48.8 & 33.2 & 97.9 & 5.9 & 44.1 & 60.4 & 43.9 \\
\hline Some/completed primary & 153 & 48.9 & 33.0 & 96.3 & 11.5 & 47.6 & 60.2 & 53.8 \\
\hline Secondary and above & 167 & 45.5 & 39.0 & 94.2 & 13.2 & 46.4 & 59.1 & 47.3 \\
\hline$P$-value & & 0.745 & 0.363 & 0.072 & 0.006 & 0.686 & 0.066 & 0.051 \\
\hline \multicolumn{9}{|l|}{ Sex of baby } \\
\hline Male & 283 & 48.3 & 32.6 & 97.7 & 8.6 & 42.2 & 56.4 & 42.9 \\
\hline Female & 290 & 47.6 & 37.0 & 95.2 & 10.3 & 49.0 & 63.5 & 52.0 \\
\hline$P$-value & & 0.853 & 0.216 & 0.038 & 0.394 & 0.057 & 0.049 & 0.018 \\
\hline \multicolumn{9}{|l|}{ Place of delivery } \\
\hline Home & 500 & 49.3 & 34.0 & 96.8 & 8.2 & 44.7 & 58.1 & 46.6 \\
\hline Health facility & 73 & 37.7 & 40.4 & 93.8 & 18.2 & 52.5 & 73.6 & 54.1 \\
\hline$P$-value & & 0.030 & 0.308 & 0.060 & 0.001 & 0.188 & 0.003 & 0.090 \\
\hline \multicolumn{9}{|l|}{ Birth order } \\
\hline First-born & 65 & 39.7 & 44.8 & 97.8 & 12.5 & 47.1 & 54.1 & 43.5 \\
\hline 2nd-4th & 256 & 48.5 & 37.2 & 94.4 & 15.5 & 48.7 & 62.6 & 49.6 \\
\hline 5th or more & 252 & 49.2 & 31.8 & 97.1 & 5.8 & 44.3 & 60.1 & 47.8 \\
\hline$P$-value & & 0.408 & 0.116 & 0.310 & 0.001 & 0.055 & 0.348 & 0.041 \\
\hline \multicolumn{9}{|l|}{ Mother's age at birth } \\
\hline$<25$ years & 149 & 44.8 & 41.1 & 94.4 & 11.3 & 43.1 & 55.4 & 43.8 \\
\hline $25-34$ years & 290 & 49.0 & 32.9 & 97.5 & 9.1 & 45.4 & 61.6 & 50.4 \\
\hline$\geq 35$ years & 134 & 48.9 & 31.9 & 96.5 & 8.2 & 48.8 & 61.6 & 45.6 \\
\hline$P$-value & & 0.549 & 0.157 & 0.264 & 0.514 & 0.489 & 0.382 & 0.257 \\
\hline \multicolumn{9}{|l|}{ Mother’s BMI } \\
\hline$<18.5 \mathrm{~kg} \mathrm{~m}^{-2}$ & 145 & 47.7 & 40.7 & 96.0 & 9.6 & 51.1 & 67.1 & 56.6 \\
\hline$\geq 18.5 \mathrm{~kg} \mathrm{~m}^{-2}$ & 421 & 48.6 & 32.6 & 96.6 & 9.3 & 43.7 & 58.0 & 44.7 \\
\hline$P$-value & & 0.850 & 0.066 & 0.659 & 0.915 & 0.094 & 0.040 & 0.007 \\
\hline National & 573 & 47.9 & 34.6 & 96.5 & 9.4 & 45.6 & 60.3 & 47.7 \\
\hline
\end{tabular}

BMI - body mass index.

The chi-square test was used to estimate $P$-values.

Height and weight were not available for seven mothers.

breast-feeding and more likely to be given artificial milk, solids, other liquids and bottle-feeds. Introduction of artificial milk, solids and other liquids to the infant was higher among mothers with BMI $<18.5 \mathrm{~kg} \mathrm{~m}^{-2}$ than in those with higher BMI.

The BPI scores of individual infants ranged from 0 to 7 with a mean of 4.4 (standard deviation 1.77). Table 3 illustrates the proportions of infants belonging to each BPI tertile according to sociodemographic category. Infants with 'low BPI' varied from $27 \%$ in the rural west region to $35 \%$ in the urban region. Prevalence of 'low BPI' was higher among infants from the lowlands (32.8\%) compared with those from the highlands (25.0\%), and in those born in health facilities (42.3\%) compared with those who delivered at home (29.8\%). 'Low BPI' was also more prevalent in infants from the richest compared with the poorest households, in first-born infants compared with the second-born and above in the family, and in mothers with $\mathrm{BMI}<18.5 \mathrm{~kg} \mathrm{~m}^{-2}$ compared with $\geq 18.5 \mathrm{~kg} \mathrm{~m}^{-2}$.

Table 4 shows the unadjusted and adjusted ORs for the associations between BPI levels and sociodemographic characteristics of infants aged $<6$ months. The adjusted 
Table 3 Proportion of infants belonging to Breast-feeding Performance Index (BPI) tertiles by sociodemographic characteristics $(n=573)$

\begin{tabular}{|c|c|c|c|c|c|}
\hline \multirow[b]{2}{*}{ Characteristic } & \multicolumn{3}{|c|}{ Breast-feeding performance category (\%) } & \multirow[b]{2}{*}{ Total (\%) } & \multirow[b]{2}{*}{$P$-value } \\
\hline & Low BPI & Average BPI & High BPI & & \\
\hline \multicolumn{6}{|l|}{ Geographical region } \\
\hline Urban & 35.4 & 32.6 & 31.9 & 100 & \\
\hline Rural west & 26.7 & 44.6 & 28.7 & 100 & \\
\hline Rural central & 28.9 & 26.2 & 45.0 & 100 & \\
\hline Rural east & 33.6 & 35.0 & 31.4 & 100 & 0.006 \\
\hline \multicolumn{6}{|l|}{ Ecological zone } \\
\hline Lowland & 32.8 & 33.5 & 33.7 & 100 & \\
\hline Highland & 25.0 & 27.4 & 47.6 & 100 & 0.030 \\
\hline \multicolumn{6}{|l|}{ Household wealth index } \\
\hline Poorest & 25.9 & 32.2 & 42.0 & 100 & \\
\hline Middle & 34.0 & 30.8 & 35.3 & 100 & \\
\hline Richest & 36.9 & 36.0 & 27.0 & 100 & 0.034 \\
\hline \multicolumn{6}{|l|}{ Maternal working status } \\
\hline Working & 32.9 & 29.0 & 38.1 & 100 & \\
\hline Non-working & 29.8 & 35.7 & 34.5 & 100 & 0.194 \\
\hline \multicolumn{6}{|l|}{ Maternal education } \\
\hline No education & 29.3 & 33.9 & 36.8 & 100 & \\
\hline Some/completed primary & 35.3 & 27.7 & 37.0 & 100 & \\
\hline Secondary and above & 30.8 & 34.5 & 34.7 & 100 & 0.439 \\
\hline \multicolumn{6}{|l|}{ Sex of baby } \\
\hline Male & 27.8 & 32.7 & 39.5 & 100 & \\
\hline Female & 34.7 & 32.1 & 33.1 & 100 & 0.087 \\
\hline \multicolumn{6}{|l|}{ Place of delivery } \\
\hline Home & 29.8 & 32.3 & 37.8 & 100 & \\
\hline Health facility & 42.3 & 32.7 & 25.0 & 100 & 0.012 \\
\hline \multicolumn{6}{|l|}{ Birth order } \\
\hline First-born & 35.6 & 26.7 & 37.7 & 100 & \\
\hline 2nd-4th & 33.7 & 34.2 & 32.1 & 100 & \\
\hline 5th or more & 23.6 & 34.0 & 42.4 & 100 & 0.058 \\
\hline \multicolumn{6}{|l|}{ Mother's age at birth } \\
\hline$<25$ years & 31.9 & 28.4 & 39.7 & 100 & \\
\hline $25-34$ years & 34.1 & 29.9 & 36.1 & 100 & \\
\hline$\geq 35$ years & 25.0 & 41.9 & 33.1 & 100 & 0.038 \\
\hline \multicolumn{6}{|l|}{ Mother's BMI } \\
\hline$<18.5 \mathrm{~kg} \mathrm{~m}^{-2}$ & 38.5 & 28.8 & 32.7 & 100 & \\
\hline$\geq 18.5 \mathrm{~kg} \mathrm{~m}^{-2}$ & 28.9 & 33.6 & 37.5 & 100 & 0.087 \\
\hline
\end{tabular}

BMI - body mass index.

The chi-square test was used to estimate $P$-values.

ORs indicated that mothers from the richest households were 1.7 (95\% CI 1.04-2.77) times more likely to have low BPI' than those from the poorest households. Female infants (OR $=1.34 ; 95 \%$ CI $0.95-1.88$ ) and those born in health facilities (OR $=1.45$; 95\% CI 0.96-2.19) had poor breast-feeding performance, but these odds ratios were not statistically significant. Low maternal BMI was predictive of poor breast-feeding performance during the first six months of life (OR $=1.79 ; 95 \%$ CI 1.27-2.52). Higher birth order (fifth and above child in the family) appeared to be protective against poor breast-feeding practices $(\mathrm{OR}=0.41 ; 95 \% \mathrm{CI} 0.21-0.80)$. Based on the multivariate analysis, maternal education level, working status and age were not associated with the overall breastfeeding performance among infants $<6$ months of age. No association was found between 'low BPI' and geographical region or ecological zone.

As illustrated in Fig. 1, the incidence of diarrhoeal diseases during the previous two weeks was $13.4 \%(95 \%$ CI 10.0-17.9\%) in the 'low BPI' group, compared with
$4.3 \%$ (95\% CI 2.3-7.9\%) in the 'average BPI' and 4.6\% (95\% CI $2.7-7.6 \%$ ) in the 'high BPI' groups. The occurrence of symptoms suggestive of acute respiratory infections among infants of the 'low BPI' group (20.7\%; 95\% CI $16.3-26.0 \%)$ was significantly higher than in the 'average BPI' (9.3\%; 95\% CI 6.5-13.2\%) and 'high BPI' (5.5\%; 95\% CI 3.4-8.6\%) groups.

\section{Discussion}

Our findings point towards the feasibility and usefulness of a composite index (BPI) to assess the overall breastfeeding performance among infants aged $<6$ months. This index should not replace the conventional indicators such as timely first suckling, exclusive breast-feeding and bottle-feeding rates, but provide supplementary information about the overall infant feeding performance. The BPI is useful when trying to identify factors associated with poor breast-feeding practices for targeting of breastfeeding education and behaviour change interventions. 
Table 4 Factors associated with low BPI*: unadjusted and adjusted OR $(n=573)$

\begin{tabular}{|c|c|c|c|c|c|c|}
\hline \multirow[b]{2}{*}{ Characteristic } & \multicolumn{3}{|c|}{ Unadjusted OR } & \multicolumn{3}{|c|}{ Adjusted OR } \\
\hline & OR & $95 \% \mathrm{Cl}$ & $P$-value & OR & $95 \% \mathrm{Cl}$ & $P$-value \\
\hline \multicolumn{7}{|l|}{ Geographical region } \\
\hline Rural central & 1.00 & & & 1.00 & & \\
\hline Urban & 1.57 & $1.05-2.34$ & 0.027 & 1.00 & $0.61-1.65$ & 1.000 \\
\hline Rural west & 1.07 & $0.65-1.74$ & 0.790 & 0.94 & $0.58-1.54$ & 0.810 \\
\hline Rural east & 1.43 & $0.93-2.20$ & 0.100 & 1.24 & $0.75-2.05$ & 0.402 \\
\hline \multicolumn{7}{|l|}{ Ecological zone } \\
\hline Highland & 1.00 & & & 1.00 & & \\
\hline Lowland & 1.75 & $1.17-2.62$ & 0.007 & 1.45 & $0.85-2.48$ & 0.170 \\
\hline \multicolumn{7}{|l|}{ Household wealth index } \\
\hline Poorest & 1.00 & & & 1.00 & & \\
\hline Middle & 1.50 & $1.01-2.23$ & 0.046 & 1.51 & $0.99-2.29$ & 0.056 \\
\hline Richest & 1.73 & $1.17-2.56$ & 0.006 & 1.70 & $1.04-2.77$ & 0.033 \\
\hline \multicolumn{7}{|l|}{ Maternal working status } \\
\hline Non-working & 1.00 & & & 1.00 & & \\
\hline Working & 1.01 & $0.72-1.41$ & 0.967 & 1.24 & $0.86-1.78$ & 0.253 \\
\hline \multicolumn{7}{|l|}{ Maternal education } \\
\hline No education & 1.00 & & & 1.00 & & \\
\hline Some/completed primary & 1.34 & $0.91-1.97$ & 0.132 & 1.09 & $0.70-1.71$ & 0.695 \\
\hline Secondary and above & 1.38 & $1.02-1.86$ & 0.037 & 0.87 & $0.59-1.28$ & 0.481 \\
\hline \multicolumn{7}{|l|}{ Sex of baby } \\
\hline Male & 1.00 & & & 1.00 & & \\
\hline Female & 1.24 & $0.91-1.70$ & 0.173 & 1.34 & $0.95-1.88$ & 0.092 \\
\hline \multicolumn{7}{|l|}{ Place of delivery } \\
\hline Home & 1.00 & & & 1.00 & & \\
\hline Health facility & 1.78 & $1.24-2.56$ & 0.002 & 1.45 & $0.96-2.19$ & 0.075 \\
\hline \multicolumn{7}{|l|}{ Birth order } \\
\hline First-born & 1.00 & & & 1.00 & & \\
\hline 2nd-4th & 0.94 & $0.58-1.53$ & 0.808 & 0.79 & $0.47-1.33$ & 0.374 \\
\hline 5th or more & 0.50 & $0.31-0.80$ & 0.004 & 0.41 & $0.21-0.80$ & 0.009 \\
\hline \multicolumn{7}{|l|}{ Mother's age at birth } \\
\hline$<25$ years & 1.00 & & & 1.00 & & \\
\hline $25-34$ years & 1.04 & $0.76-1.43$ & 0.785 & 1.38 & $0.92-2.08$ & 0.119 \\
\hline$\geq 35$ years & 0.69 & $0.45-1.05$ & 0.080 & 1.25 & $0.67-2.34$ & 0.481 \\
\hline \multicolumn{7}{|l|}{ Mother's BMI } \\
\hline$<18.5 \mathrm{~kg} \mathrm{~m}^{-2}$ & 1.00 & & & 1.00 & & \\
\hline$\geq 18.5 \mathrm{~kg} \mathrm{~m}^{-2}$ & 1.68 & $1.19-2.36$ & 0.003 & 1.79 & $1.27-2.52$ & 0.001 \\
\hline
\end{tabular}

BPI - Breast-feeding Performance Index; OR - odds ratio; $\mathrm{Cl}$ - confidence interval; $\mathrm{BMI}$ - body mass index. Multiple logistic regression analysis was used to adjust the ORs for the characteristics listed in the table.

${ }^{*}$ Low BPI = lowest tertile of BPI.

However, a detailed examination of the individual infant feeding indicators in the subpopulations with low BPI would still be needed when designing interventions. The index could also be useful in establishing the association between breast-feeding and infant morbidity, and evaluating the overall effect of interventions to promote breast-feeding.

Simplicity is one of the major concerns in constructing indices. The proposed scoring system is simple and easily applicable in other settings and countries with representative data such as DHS, national nutritional surveys, or appropriately designed surveys of smaller geographic areas. However, the same index with equal weights cannot be applied without data on all seven indicators.

We have combined indicators that refer to different time periods in a single summary index of infant feeding in populations. The use of indicators for current practices based on feeding patterns in the 24 hours prior to interview may have resulted in some non-differential misclassification due to day-to-day variation in the intake of any solids and non-breast-milk liquids. We have accepted this limitation because this approach is well established in many surveys of infant feeding. Recall bias may limit the validity of past information but since the index is for populations of infants $<6$ months old, we assume that any inadequate recall of early infant feeding practices by mothers would be minimal. Despite these limitations, the combination of these indictors referring to different time periods can provide an estimate for overall infant feeding practices in populations of young infants.

There is no clear evidence to justify giving different weights for different components. We considered an alternative method using PCA to weight the components of the index, but this more complex method produced similar weights and results to those of the equal weight method. The tertiles of the equal weight method were highly and significantly correlated $(r=0.9346$, $P<0.0001)$ with those of the PCA method. 

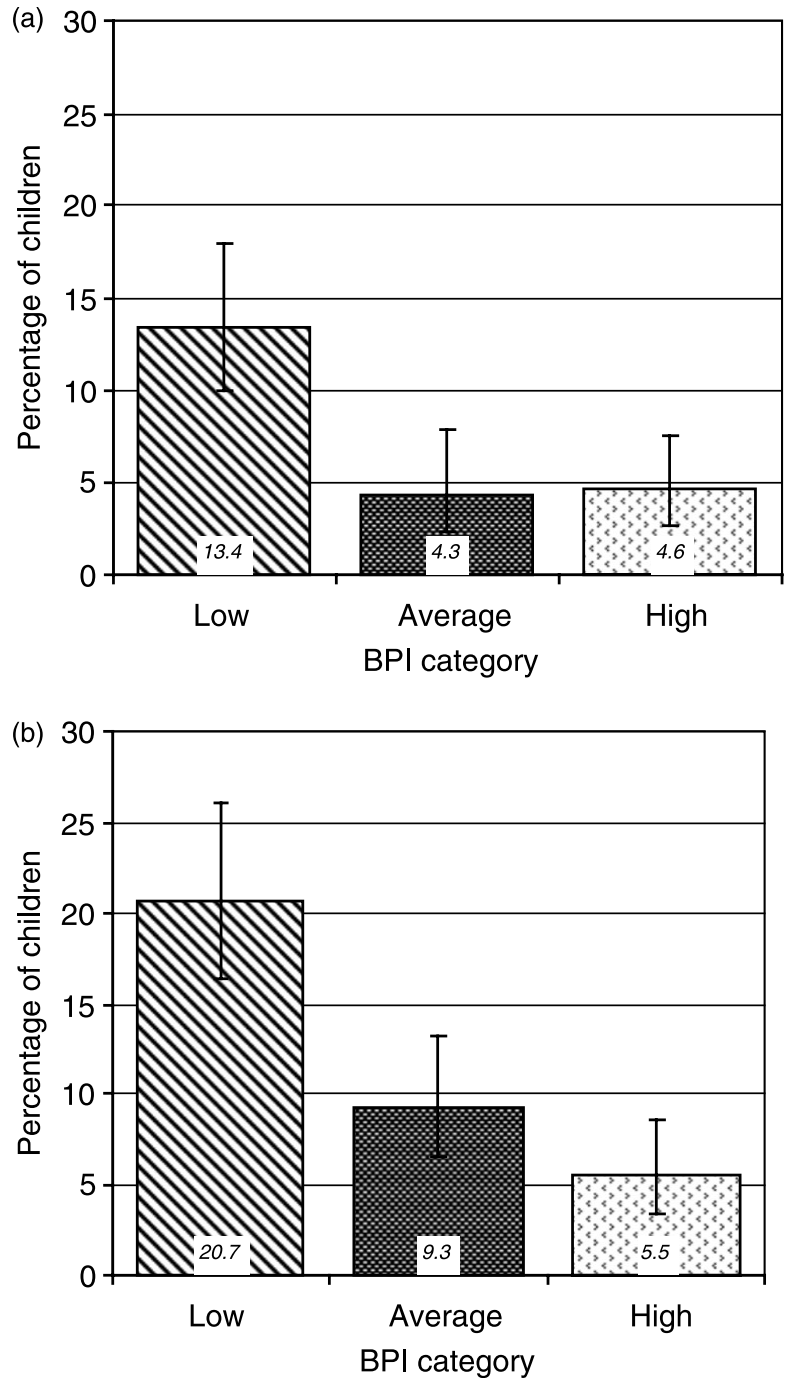

Fig. 1 Two-week period prevalence of (a) diarrhoea and (b) acute respiratory infections by Breast-feeding Performance Index (BPI) category (percentage with $95 \%$ confidence interval shown by vertical bars)

Our results indicate that $<6$-month-old infants from the richest households were at a greater risk of having poor breast-feeding practices than infants from the poorest households. These results are supported by studies from India and Africa that have revealed lower current breastfeeding and higher bottle-feeding rates among socioeconomically privileged mothers ${ }^{8,25,26}$. However, a review of factors associated with the initiation and continuation of breast-feeding among Western women has highlighted a less consistent association between socio-economic status and breast-feeding practices ${ }^{7}$. Evidence from Timor-Leste suggests that breast-feeding promotion programmes should pay more attention to mothers from the richest families in order to achieve and maintain high breastfeeding target rates.

Maternal nutritional status was a strong predictor of breast-feeding behaviours. Previous studies have recognised maternal overweight and obesity as risk factors for initiation and duration of breast-feeding ${ }^{27-29}$. Results from our study revealed that maternal undernutrition is also a strong predictor of poor breast-feeding practices. Mothers with BMI $<18.5 \mathrm{~kg} \mathrm{~m}^{-2}$ were 1.79 times (95\% CI 1.27-2.52) more likely to have a 'low BPI' than those with BMI $\geq 18.5 \mathrm{~kg} \mathrm{~m}^{-2}$. This could be due to insufficient milk production by these thin mothers or their belief they do not having enough milk. The implications for practice of our findings are twofold: in the short term breast-feeding promotion should be focused on mothers with low BMI; but in the long term interventions to improve the nutritional status of women in Timor-Leste are essential.

Our study indicated that the first-born infants were often inadequately breast-fed. Evidence from previous studies suggests that successful breast-feeding is strongly influenced by parity ${ }^{27,30}$. As primiparous mothers have no previous experience with breast-feeding, it is important to target this group in breast-feeding promotion and support programmes. Family members and health-care providers have a significant role to play in providing psychosocial and physical support for these mothers.

Our findings revealed that there was a significantly higher proportion of infants with adverse health outcomes such as diarrhoeal diseases and acute respiratory infections among the 'low BPI' group compared with the 'average BPI' and 'high BPI' groups. These associations suggest the usefulness of the index in assessing health outcomes of infants aged $<6$ months. The feeding index developed by Ruel and Menon for children aged 6-36 months has been successfully used to estimate the strength of the association between child feeding practices and child nutritional status ${ }^{3,17,18}$. Some of these studies found that the child feeding index was associated with heightfor-age $Z$-score ${ }^{3,17}$ while others did not find any association $^{18}$. It is less likely that the BPI will be associated with anthropometric indicators in infants because other factors, such as birth weight and maternal malnutrition, will have a greater impact on the anthropometric status of these young infants ${ }^{31,32}$. However, the BPI might be useful to predict growth and this question needs to be examined in longitudinal studies. Similarly, a more rigorous assessment would be needed to support the association between BPI and infant morbidity while taking into account potential confounding variables like age and home environments.

One limitation of composite indices is that they obscure the individual practices that constitute the index, and thus may mask the existence of important relationships between specific practices and the determinants or outcomes of interest. The complex association between BPI, household wealth index and BMI is a good example where one cannot explain the associations without looking into individual practices. Despite high BMI, rich mothers had a significantly higher bottle-feeding rate and gave formula feeds to their infants (see Table 2). These 
practices led to a low BPI in rich mothers. Therefore, the BPI should be applied with careful consideration of its appropriateness for individual assessments, while also assessing conventional indicators. Our study did not investigate the usefulness of a composite index of breastfeeding in monitoring and evaluation of interventions. A single cross-sectional dataset was not suitable for such an evaluation. We recommend further studies to address this topic using before-and-after quasi experiments or randomised controlled trials in which a variety of indicators, including the composite BPI, would be used to evaluate the impact of the intervention.

In conclusion, our findings indicate that creating a composite index to assess the overall breast-feeding performance among infants $<6$ months of age is feasible using data available in a DHS from Timor-Leste. The Breast-feeding Performance Index can be effectively used to identify vulnerable groups that could be targeted by breast-feeding promotion interventions. The index can also be helpful in establishing the association between breast-feeding and infant morbidity outcomes.

\section{Acknowledgements}

Sources of funding: The World Bank Trust Fund for East Timor funded the DHS and the University of Colombo, Sri Lanka sponsored a fellowship for the first author (U.S.).

Conflict of interest declaration: There are no conflicts of interest in this work for any of the authors.

Authorship responsibilities: U.S. designed and conducted the analysis and prepared the manuscript; M.J.D. collected the data, assisted with the current analyses and contributed to the manuscript; K.E.A. assisted with the analyses and the preparation of the manuscript.

Acknowledgements: The authors extend their thanks to the Timor-Leste Ministry of Health for releasing the DHS data for these analyses. We are also grateful to Professor Graham Vimpani, Clinical Chair of the Kaleidoscope in Greater Newcastle, for his support for this research activity.

\section{References}

1 MkNelly B, Dunford C. Impact of Credit with Education on Mothers and their Young Children's Nutrition: Lower Pra Rural Bank Credit with Education Program in Ghana. Program in International Nutrition. Davis, CA: University of California, 2005. Also available at http://www.ffhtechnical. org/publications/pdfs/CwE_R4_GhanaImpact.pdf

2 Arimond M, Ruel MT. Progress in Developing an Infant and Child Feeding Index: An Example using the Ethiopia Demographic and Health Survey 2000. Washington, DC: International Food Policy Research Institute, 2002. Also available at http://www.ifpri.org/divs/fcnd/dp/papers/ fondp143.pdf

3 Ruel MT, Menon P. Child feeding practices are associated with child nutritional status in Latin America: innovative uses of the Demographic and Health Surveys. Journal of Nutrition 2002; 136: 1180-7.
4 Dewey K, Heinig MJ, Nommsen-Rivers L. Differences in morbidity between breast-fed and formula-fed infants. Journal of Pediatrics 1995; 126: 696-702.

5 Arifeen S, Black RE, Antelman G, Baqui A, Caulfield L, Becker S. Exclusive breastfeeding reduces acute respiratory infection and diarrhoea deaths among infants in Dhaka slums. Pediatrics 2001; 108: E67.

6 Richards M, Hardy R, Wadsworth ME. Long-term effects of breast-feeding in a national birth cohort: educational attainment and midlife cognitive function. Public Health Nutrition 2002; 5: 631-5.

7 Scott JA, Binns CW. Factors associated with the initiation and duration of breastfeeding: a review of the literature. Breastfeeding Review 1999; 7: 5-16.

8 El-Gilany AH. Breastfeeding indicators in Dakahlia Governorate. Eastern Mediterranean Health Journal 2003; 9: 961-73.

9 Aidam BA, Perez-Escamilla R, Lartey A, Aidam J. Factors associated with exclusive breastfeeding in Accra, Ghana. European Journal of Clinical Nutrition 2005; 59: 789-96.

10 World Health Organization (WHO). Infant and Young Child Nutrition: Global Strategy on Infant and Young Child Feeding. Resolution WHA55/15, Geneva: WHO, 2002.

11 Jones G, Steketee RW, Black RE, Bhutta ZA, Morris SS. How many child deaths can we prevent this year? Lancet 2003; 362: $65-71$.

12 Sinusas K, Gagliardi A. Initial management of breastfeeding. American Family Physician 2001; 64: 981-8.

13 Howard CR, Howard FM, Lanphear B, Eberly S, deBlieck E, Oakes D, et al. Randomized clinical trial of pacifier use and bottle-feeding or cupfeeding and their effect on breastfeeding. Pediatrics 2003; 111: 511-8.

14 Perez-Escamilla R, Segura-Millan S, Canahuati J, Allen H. Prelacteal feeds are negatively associated with breastfeeding outcomes in Honduras. Journal of Nutrition 1996; 126: $2765-73$.

15 Howie PW, Forsyth JS, Ogston SA, Clark A, Florey CD. Protective effect of breastfeeding against infection. British Medical Journal 1990; 300: 11-6.

16 Temboury MC, Otero A, Polanco I, Arribas E. Influence of breast-feeding on the infant's intellectual development. Journal of Pediatric Gastroenterology and Nutrition 1994; 18: $32-6$.

17 Arimond M, Ruel MT. Dietary diversity is associated with child nutritional status: evidence from 11 Demographic and Health Surveys. Journal of Nutrition 2004; 134: 2579-85.

18 Ntab B, Simondon KB, Milet J, Cisse B, Sokhna C, Boulanger $\mathrm{D}$, et al. A young child feeding index is not associated with either height-for-age or height velocity in rural Senegalese children. Journal of Nutrition 2005; 135: 457-64.

19 Wilmoth TA, Elder JP. An assessment of research on breastfeeding promotion strategies in developing countries. Social Science \& Medicine 1995; 41: 579-94.

20 Davies-Adetugbo A. Promotion of breastfeeding in the community: impact of health education programme in rural communities in Nigeria. Journal of Diarrhoeal Diseases Research 1996; 14: 5-11.

21 Merten S, Dratva J, Ackermann-Liebrich U. Do Baby-Friendly Hospitals influence breastfeeding duration on a national level? Pediatrics 2005; 116: e702-8.

22 Ministry of Health and National Statistics Office Timor-Leste, The Australian National University, University of Newcastle, ACIL Australia Pty Ltd. Timor-Leste 2003 Demographic and Health Survey. Newcastle: University of Newcastle, 2004.

23 United Nations Children's Fund (UNICEF). UNICEF Statistics, Multiple Indicator Cluster Surveys (MICS) - Assessing the economic status of housebolds [online]. Available at http:// www.childinfo.org/MICS2/finques/gj00106a.htm. Accessed 23 April 2005.

24 Filmer D, Pritchett L. Estimating Wealth Effects without Expenditure Data or Tears: An Application to Educational 
Enrolments in States of India. Working Paper No. 1994. Washington, DC: World Bank Policy Research, 1998.

25 Kumar S, Nath LM, Reddaiah VP. Factors influencing prevalence of breastfeeding in a resettlement colony of New Delhi. Indian Journal of Pediatrics 1989; 56: 385-91.

26 Lakati A, Binns C, Stevenson M. Breast-feeding and the working mother in Nairobi. Public Health Nutrition 2002; 5 : 715-8.

27 Dewey KG, Nommsen-Rivers LA, Heinig MJ, Cohen RJ. Risk factors for suboptimal infant breastfeeding behaviour, delayed onset of lactation, and excess neonatal weight loss. Pediatrics 2003; 112: 607-19.

28 Li R, Jewell S, Grummer-Strawn L. Maternal obesity and breast-feeding practices. American Journal of Clinical Nutrition 2003; 77: 931-6.
29 Kugyelka JG, Rasmussen KM, Frongillo EA. Maternal obesity is negatively associated with breastfeeding success among Hispanic but not Black women. Journal of Nutrition 2004; 134: $1746-53$.

30 Lawoyin TO, Olawuyi JF, Onadeko MO. Factors associated with exclusive breastfeeding in Ibadan. Nigeria. Journal of Human Lactation 2001; 17: 321-5.

31 Marins VMR, Almeida RMVR. Undernutrition prevalence and social determinants in children aged 0-59 months. Niteroi, Brazil. Annals of Human Biology 2002; 29: 609-18.

32 Espo M, Kulmala T, Maleta K, Cullinan T, Salin ML, Ashorn P. Determinants of linear growth and predictors of severe stunting during infancy in rural Malawi. Acta Paediatrica 2002; 91: 1364-70. 